\title{
Changes in gastrointestinal symptoms and food tolerance 6 months following weight loss surgery: associations with dietary changes, weight loss and the surgical procedure
}

Anne Stine Kvehaugen ${ }^{1 *}$ (i) and Per G. Farup ${ }^{2,3}$

\begin{abstract}
Background: Gastrointestinal (Gl) co-morbidity is common in obese patients, but the effect of weight loss surgery on $\mathrm{Gl}$ symptoms is incompletely elucidated. The aims of the present study were to explore changes in $\mathrm{Gl}$ symptoms and food tolerance following weight loss surgery and to study whether such changes were associated with dietary modifications and/or the type of surgical procedure [Roux-en-Y Gastric Bypass (RYGB) versus Vertical Sleeve Gastrectomy (VSG)].

Methods: Participants: Patients with morbid obesity scheduled for weight loss surgery. The patients filled in paperbased questionnaires addressing diet, Gl symptoms (bloating, pain, satiety, constipation and diarrhea) and food tolerance/quality of alimentation (satisfaction about current food intake, tolerance to specific foods and frequency of vomiting/regurgitation/reflux) 6 months prior to and 6 months after the surgery. Patients with pre-existing major Gl co-morbidity or previous major Gl surgery were excluded.

Results: Fifty-four patients (RYGBNSG: 43/11) were included. Constipation and satiety increased and food tolerance decreased significantly after the surgery (all $p$-values $<0.05$ ). The increase in satiety was significantly more notable after VSG than after RYGB $(p<0.05)$.The increase in satiety also correlated with an overall reduction in food tolerance (rho: $-0.488, p<0.01$ ). Divergent changes were seen in the frequency of vomiting/regurgitation/reflux, with a decline after RYGB $(p=0.01)$ and an increase after VSG $(p=0.06)$. Intakes of energy, macronutrients, fiber and fluid decreased significantly after the surgery (all $p$-values $<0.05$ ), but did not correlate with the changes in constipation, satiety or food tolerance (all $p$-values $>0.05$ ). Pre-operatively, total energy intake correlated with bloating and abdominal pain (rho $=0.343$ and 0.310 respectively, $p<0.05$ for both), but these correlations did not persist 6 months after the surgery (rho $=0.065$ and 0.054 respectively, $p>0.05$ for both).

Conclusion: A high caloric intake may explain some of the Gl symptoms experienced by non-operated obese patients. The worsening or new-onset of symptoms post-surgery is likely due to anatomical or physiological alterations following surgery. The increase in satiety and the decrease in food tolerance are likely explained by the restrictive nature of the surgeries, as satiety increased more after VSG than after RYGB and correlated with an overall reduction in food tolerance.
\end{abstract}

Keywords: Obesity, Gastrointestinal, Diet, Food tolerance, Weight loss, Weight loss surgery, Roux-en-Y gastric bypass, Vertical sleeve gastrectomy

\footnotetext{
*Correspondence: akvehaugen@yahoo.no

'Department of Surgery, Innlandet Hospital Trust, Kyrre Greppsgate 11, 2819

Gjøvik, Norway

Full list of author information is available at the end of the article
}

(c) The Author(s). 2018 Open Access This article is distributed under the terms of the Creative Commons Attribution 4.0 International License (http://creativecommons.org/licenses/by/4.0/), which permits unrestricted use, distribution, and reproduction in any medium, provided you give appropriate credit to the original author(s) and the source, provide a link to the Creative Commons license, and indicate if changes were made. The Creative Commons Public Domain Dedication waiver (http://creativecommons.org/publicdomain/zero/1.0/) applies to the data made available in this article, unless otherwise stated. 


\section{Background}

Weight loss surgery is considered an effective tool for the treatment of obesity [1]. In addition to the resultant weight loss, this type of intervention may also ameliorate or reduce associated co-morbidities and risk factors such as hypertension, lipid abnormalities, fasting plasma glucose, HbA1c, metabolic syndrome and type 2 diabetes mellitus [1, 2]. Gastrointestinal (GI) co-morbidity is also common in obese patients [3-5], but less is known about how GI symptoms change pre- to post surgery. A direct relationship between Body Mass Index (BMI) and specific GI symptoms and bowel habits has been shown $[6,7]$, and it has been speculated that excessive food (nutrient) intake could explain some of these symptoms $[3,6,7]$. Thus, weight reduction per se and/or alterations in diet following weight loss surgery could potentially relieve the GI symptoms experienced by obese patients. On the other hand, weight loss surgeries induce anatomical changes of the GI tract by restricting the gastric volume and, depending on the type of surgery, may also induce some degree of malabsorption. A change in the tolerance to certain foods has also been described as a side effect of these surgeries [8-11]. A broader understanding of the associations between the changes in diet, weight, food tolerance and GI symptoms, as well as the effect of surgery and the type of surgical procedure on GI symptoms and food tolerance is therefore warranted in order to improve the nutritional and medical care of these patients.

Aim of the present study was to explore changes in GI symptoms and food tolerance from 6 months prior- to 6 months after weight loss surgery and to explore whether such changes were associated with alterations in dietary intake, weight loss or the type of surgery [Roux-en-Y Gastric Bypass (RYGB) and Vertical Sleeve Gastrectomy (VSG)].

\section{Methods}

\section{Patients and study design}

The study was performed at the unit for morbid obesity at Innlandet Hospital Trust, Gjøvik, Norway. Patients referred for morbid obesity $\left[\mathrm{BMI} \geq 40 \mathrm{~kg} / \mathrm{m}^{2}\right.$ or $\mathrm{BMI} \geq$ $35 \mathrm{~kg} / \mathrm{m}^{2}$ with obesity related complications (e.g. diabetes, hypertension, sleep apnoea, musculoskeletal problems)] were included in a comprehensive study from December 2012 to September 2014. The patients were evaluated for bariatric surgery or non-surgical treatment of obesity. Medical history was taken, physical examination was performed and a blood sample was collected for further analyses. The patients filled in paper-based questionnaires including a case-report form (providing data such as demographics, clinical data and co-morbidities) and a food frequency questionnaire (FFQ) designed to study the usual diet. The FFQ has been prepared and validated by the University of Oslo $[12,13]$. Daily intake of food, nutrients and energy was calculated by Department of Nutrition at the University of Oslo by their in-house calculation program (KBS, version 7.3, food database AE-14). The food composition database in the calculation program is based on the official Norwegian food composition table from 2016 [14] and is supplemented with additional food items. The degree of specific GI complaints was assessed with the Gastrointestinal Symptom Rating Scale - Irritable Bowel Syndrome (GSRS-IBS) [15]. The questionnaire contained 13 questions with responses ranging from 1 to 7 (no discomfort at all to very severe discomfort). The questions were clustered into the following dimensions; GSRS-diarrhea, -constipation, -bloating, -pain and -satiety [15], and a mean value for the items in each dimension were calculated. The questionnaire "Quality of alimentation" [16] was used for the evaluation of food tolerance. An overall food tolerance score (FTS): range 1-27, with increasing values representing increased food tolerance, was calculated based on the following responses: 1) an overall assessment of the patient's satisfaction about food intake [range: 1 (very poor) to 5 (excellent)]; 2) an evaluation of tolerance of eight different types of food [range 0-16; range for each food item: 0 (can't eat), 1 (can eat with some difficulties/restrictions), 2 (can eat without any difficulties)] and 3) frequency of vomiting/regurgitation/ reflux $(\mathrm{V} / \mathrm{R} / \mathrm{R})$; range: 0 (daily), 2 (three or more times a week), 4 (up to twice a week), 6 (never) [16]. As the terms "reflux" and "regurgitation" are often used interchangeably, our local, non-validated translation of the food tolerance questionnaire included synonyms of both expressions, compared to "regurgitation" only as per original questionnaire.

Patients scheduled for surgery (RYGB or VSG) were included in a longitudinal follow-up study. Repeat measures of the above were performed at the pre-operative day ( 6 months after the first visit), and in relation to the routine follow-up visits at the hospital (6 weeks, 6 months, 12 months and 24 months after the surgery). Collection of data for research purposes were performed at all, but the 6-week appointment. Dietary data were not obtained at the pre-operative day. The present study compared data obtained from the first visit at the hospital $\sim 6$ months prior to the surgery, with data obtained from the 6 month follow-up visit after surgery. All patients signed an informed written consent. Patients who completed the FFQs and had data on GI symptoms, food tolerance and anthropometrics at both time points were included. Patients who withdrew their consent for participation were excluded, as were patients with pre-existing major GI co-morbidity or previous major GI surgery.

\section{Dietary counseling and follow-up}

The patients received dietary and lifestyle counseling at enrolment as well as at the follow-up visits. The 
pre-surgery intervention has been described in more detail previously [17]. The patients also received oral and written information regarding the dietary principles to be followed after the surgery (e.g. selection of foods low in energy, but high in protein and fiber, consuming small portion sizes, chewing the food well, not drinking with meals etc). After the surgery, patients consumed liquid meals for one week and soft/pureed meals the next two weeks (week 2 and 3 after the surgery). From the 4th week, solid foods could be introduced. All patients (without differences between the surgery groups) were prescribed the following daily supplements, starting 1014 days after the surgery: a multivitamin- and mineral supplement, calcium carbonate with vitamin D (1000 mg/800 IU) and oral iron (corresponding to $100 \mathrm{mg} \mathrm{Fe}{ }^{2+}$ for men and post-menopausal women and $200 \mathrm{mg} \mathrm{Fe}{ }^{2+}$ for pre-menopausal women). The patients also received vitamin B12-injections every three months after the surgery. Compliance with the dietary advices, including the use of supplements, was monitored at the follow-up visits. Blood samples were also collected and based on the test results, adjustments of the supplements were made if indicated.

\section{Surgical procedures}

Standardized laparoscopy with four trocars and a liver retractor. In case of sliding hernia this was repositioned, and a hiatal repair was performed with non-absorbable multifilament 1 suture.

\section{VSG}

The gastro-colic and -splenic ligaments were divided close to the greater curvature of the stomach, posterior adhesions to the pancreas were released, and the left diaphragmatic crus was exposed. The stomach was divided with linear staplers over a bougiesize of 35 French, from 3 to $4 \mathrm{~cm}$ from the pylorus to $0-1 \mathrm{~cm}$ from the angle of Hiss. The whole stapler line was inverted with slowlyabsorbable 2-0 monofilament suture. The resected part of the stomach was removed.

\section{RYGB}

The gastric pouch was created with linear staplers, a total line of $100-150 \mathrm{~mm}$. The Roux-en-Y bypass was created with a $50 \mathrm{~cm}$ bilio-pancreatic limb $(100 \mathrm{~cm}$ in patients with type 2 diabetes mellitus) and a $150 \mathrm{~cm}$ alimentary limb. The gastro-enterostomy was fashioned with $30-45 \mathrm{~mm}$ linear stapler and one row of $2-0$ slowly absorbable monofilament suture. The omentum was not divided. The entero-anastomosis was created with a $45 \mathrm{~mm}$ linear stapler and closure with $2-0$ slowly absorbable monofilament suture. The mesentery at the entero-anastomosis was divided to the vascular arcade $(4-7 \mathrm{~cm})$ and the opening in the mesentery and
Petersen's space were both closed with double-rows of single non-absorbable staplers.

\section{Statistical analyses}

Data analyses were performed with IBM SPSS Statistics for Windows, Version 23 (IBM Corp., Armonk, N.Y., USA). For continuous data, comparisons between two independent groups were analyzed with the independent sample t-test if data were normally distributed; otherwise, or in case of ranked data, the non-parametric Mann Whitney U-test was used. Related samples were similarly analyzed with the paired sample t-test or the Wilcoxon Signed Rank test. Categorical data were analyzed with $\chi^{2}$ statistics. Data were presented as mean with standard deviation (SD), median with 25-75 percentiles or number (n) and percent. Changes from pre- to post-surgery were computed as post-surgery values minus pre-surgery values for all variables. Correlations between variables were tested with Spearman's correlation (rho). Association analyses were considered explorative.

\section{Results}

\section{Patients and material}

In all, 99 patients underwent either RYGB $(n=81)$ or VSG $(n=18)$ surgery. Of these, 17 patients withdrew their consent for participation at the 6 months follow up and were excluded, as were patients with pre-existing major GI co-morbidity (celiac disease; $n=$ 3 ) or previous major GI surgery (gastric banding; $n=2$, fundoplication; $n=1$ ). Fifty-four (RYGB/VSG: 43/11) of the remaining patients had sufficient data at both time points allowing for comparisons of changes in diet, anthropometrics, food tolerance and/or GI symptoms and were selected for the present study. Age at enrolment was significantly higher [mean (SD): 45.7 (7.74) vs.40.2 (8.36), $p=0.001$ ] in the selected study population compared to the patients not included in the study. There were no significant differences between the groups with respect to pre-surgery weight, BMI, GI symptoms or other co-morbidities (all $p$-values $>0.05$ ).

Tables 1 and 2 shows the patient characteristics, GI symptoms, food tolerance measures and the dietary data for the included patients before and 6 months after the surgery, as well as the change in each variable between the two time points. Data on tolerance to individual food items are not displayed in the table. There were significant reductions post-surgery in the tolerance to red meat, rice, pasta and bread (all $P$-values < $0.05)$, but not to white meat, fish, vegetables and lettuce (all P-values $>0.05$ ). The majority of the intolerant patients responded that they could eat the food with some difficulties (data not shown). 
Table 1 Changes in patients` characteristics, Gl-symptoms and food tolerance from pre- to 6 months post-surgery

\begin{tabular}{|c|c|c|c|c|c|}
\hline & $N$ & Pre-surgery & 6 months post-surgery & Change $^{a}$ & $P$-value \\
\hline Age, years & 54 & $45.7(7.74)$ & NA & NA & NA \\
\hline Gender (male/female), n (\%) & 54 & $10(18.5) / 44(81.5)$ & NA & NA & NA \\
\hline Type of surgery (RYGB/NSG), n (\%) & 54 & NA & $43(79.6) / 11(20.4)$ & NA & NA \\
\hline Weight (kg) & 54 & 120 (110 to 133$)$ & 84.8 (78.1 to 95.1$)$ & $-34.3(-40.3$ to -29.0$)$ & $<0.001^{*}$ \\
\hline $\mathrm{BMl}, \mathrm{kg} / \mathrm{m}^{2}$ & 54 & $41.6(3.47)$ & $29.8(3.69)$ & $-11.8(2.84)$ & $<0.001^{*}$ \\
\hline GSRS-IBS Pain (1-7) & 50 & $1.50(1.00$ to 2.50$)$ & 2.00 (1.00 to 2.50$)$ & $0.00(0.00$ to 1.00$)$ & 0.157 \\
\hline GSRS-IBS Satiety (1-7) & 51 & $1.00(1.00$ to 1.50$)$ & 2.50 (1.50 to 3.00$)$ & $1.00(0.00$ to 1.50$)$ & $<0.001^{*}$ \\
\hline GSRS-IBS Bloating (1-7) & 49 & 1.67 (1.00 to 3.00$)$ & 2.00 (1.67 to 3.17$)$ & $0.00(-0.33$ to 1.00$)$ & 0.094 \\
\hline GSRS-IBS Constipation (1-7) & 50 & $1.00(1.00$ to 2.00$)$ & 1.00 (1.00 to 2.50$)$ & 0.00 (0.00 to 1.12$)$ & $0.030^{*}$ \\
\hline GSRS-IBS Diarrhea (1-7) & 50 & $1.25(1.00$ to 1.81$)$ & 1.50 (1.00 to 2.25$)$ & $0.12(-0.25$ to 0.56$)$ & 0.192 \\
\hline FTS (1-27) & 53 & 24.0 (22.0 to 26.0$)$ & $22.0(20.0$ to 25.0$)$ & $-1.00(-4.50$ to 1.00$)$ & $0.006^{*}$ \\
\hline Satisfaction of current eating $(1-5)^{b}$ & 53 & 4.00 (4.00 to 5.00$)$ & $4.00(4.00$ to 5.00$)$ & $0.00(-1.00$ to 1.00$)$ & 0.258 \\
\hline Sum score of tolerance to eight individual food items $(0-16)^{c}$ & 54 & $16.0(14.7$ to 16.0$)$ & $14.0(12.0$ to 15.2$)$ & $-2.00(-3.25$ to 0.00$)$ & $<0.001^{*}$ \\
\hline Vomiting/Regurgitation/Reflux (0-2-4-6; daily to never) & 54 & 4.00 (4.00 to 6.00$)$ & $6.00(4.00$ to 6.00$)$ & $0.00(-2.00$ to 2.00$)$ & 0.120 \\
\hline
\end{tabular}

Data are given as median (25-75 percentiles); mean (SD) or $n$ (\%). ${ }^{a}$ The changes were computed as post-surgery values minus pre-surgery values for each patient (paired samples). P-values were obtained by the Wilcoxon Signed Rank Test and the Paired-Sample T-test. GSRS-IBS: Gastrointestinal Symptom Rating ScaleIrritable Bowel Syndrome (range 1-7: Increasing values indicates increasing symptoms). FTS: Food Tolerance Score (range 1-27: Increasing values indicates better tolerance). ${ }^{b}$ Very unsatisfied to very satisfied. ${ }^{c}$ Range of each food item: 0 (can't eat); 1 (can eat with some difficulties); 2 (can eat without any difficulties). ${ }^{*}$ Statistically significant $p<0.05$

\section{Associations between Gl symptoms, food tolerance, diet and anthropometrics}

Table 3 shows the correlations between the GI symptoms, food tolerance, weight, BMI, and dietary intakes before the surgery (A) and 6 months after the surgery (B). Correlations between the changes in these variables from pre- to 6 months after the surgery were also examined, and significant correlations were noted for the following variables: A decline in food tolerance was associated with a decline in weight and BMI (rho: 0.283 and 0.298 respectively, $P$-values $<0.05$ for both) and with an increase in satiety and abdominal pain (rho: -0.488 and -0.362 respectively, P-values $<0.01$ for both). A decline in fat intake was associated with a decline in bloating (rho: $0.303, p<0.05$ ), whereas a decline in sugar intake was associated with a decline in abdominal pain (rho: $0.513, p<0.01$ ).

\section{RYGB vs. VSG}

Patient characteristics and dietary data were similar between the two surgery groups at enrolment in the study (all $P$-values $>0.05$ ) and the variables did not change

Table 2 Changes in daily dietary intakes from pre- to 6 months post-surgery

\begin{tabular}{|c|c|c|c|c|c|}
\hline & $N$ & Pre-surgery & 6 months post-surgery & Change $^{a}$ & $P$-value \\
\hline Energy, kJ/kcal & 54 & $\begin{array}{l}9859 \text { (7533 to } 12,424) / \\
2356 \text { (1800 to } 2969)\end{array}$ & $\begin{array}{l}5298(4272 \text { to } 6541) / \\
1266(1021-1563)\end{array}$ & $\begin{array}{l}-4515(-6514 \text { to }-2110) / \\
-1079(-1557 \text { to }-504)\end{array}$ & $<0.001^{*}$ \\
\hline Fat, $g$ & 54 & $89.7(58.5$ to 121$)$ & 45.0 (39.7 to 54.3$)$ & $-36.0(-70.0$ to -15.7$)$ & $<0.001^{*}$ \\
\hline Fat, E\% & 54 & 35.6 (31.3 to 38.6$)$ & $34.3(28.5$ to 38.1$)$ & $-1.25(-4.80$ to 1.92$)$ & 0.159 \\
\hline Protein, $g$ & 54 & 103 (81.6 to 127$)$ & $65.1(52.1$ to 73.4$)$ & $-39.6(-54.2$ to -24.0$)$ & $<0.001^{*}$ \\
\hline Protein, E\% & 54 & 18.0 (15.9 to 19.6$)$ & 20.1 (18.2 to 22.3$)$ & 2.25 (0.05 to 5.47$)$ & $<0.001^{*}$ \\
\hline Carbohydrates, g & 54 & 245 (194 to 318$)$ & $133(94.5$ to 174$)$ & $-111(-158$ to -61.5$)$ & $<0.001^{*}$ \\
\hline Carbohydrates, E\% & 54 & 42.5 (40.1 to 46.7$)$ & $42.6(35.7$ to 47.1$)$ & $-0.65(-7.17$ to 3.90$)$ & 0.247 \\
\hline Sugar, g & 54 & 24.1 (14.3 to 42.5$)$ & 11.9 (4.57 to 22.9$)$ & $-14.2(-28.5$ to -3.12$)$ & $<0.001^{*}$ \\
\hline Sugar, E\% & 54 & 4.80 (3.00 to 6.82$)$ & 3.70 (1.67 to 6.52$)$ & $-1.10(-3.87$ to 1.25$)$ & $0.042^{*}$ \\
\hline Fiber, $g$ & 54 & $33.8(9.42)$ & $20.9(7.91)$ & $-12.9(9.85)$ & $<0.001^{*}$ \\
\hline Water total, g & 54 & 3602 (2816 to 4756$)$ & 2516 (2152 to 3120$)$ & $-1078(-1981$ to -148$)$ & $<0.001^{*}$ \\
\hline Food and beverages total, $\mathrm{g}$ & 54 & 4357 (3389 to 5636) & 2995 (2503 to 4190) & $-1090(-2332$ to -34.1$)$ & $<0.001^{*}$ \\
\hline
\end{tabular}

Data are given as median (25-75 percentiles) or mean (SD). ${ }^{\text {a }}$ The changes were computed as post-surgery values minus pre-surgery values for each patient (paired samples). P-values were obtained by the Wilcoxon Signed Rank Test and the Paired-Sample T-test.* Statistically significant $p<0.05$ 
Table 3 Correlations between Gl symptoms, food tolerance, weight, BMI and dietary intakes

\begin{tabular}{|c|c|c|c|c|c|c|}
\hline & $\begin{array}{l}\text { GSRS-IBS } \\
\text { Satiety }\end{array}$ & $\begin{array}{l}\text { GSRS-IBS } \\
\text { Pain }\end{array}$ & $\begin{array}{l}\text { GSRS-IBS } \\
\text { Bloating }\end{array}$ & GSRS-IBS Constipation & $\begin{array}{l}\text { GSRS-IBS } \\
\text { Diarrhea }\end{array}$ & FTS \\
\hline Weight, kg & $\begin{array}{l}\text { A: }-0.046 \\
\text { B: }-0.253\end{array}$ & $\begin{array}{l}\text { A: } 0.012 \\
\text { B: }-0.200\end{array}$ & $\begin{array}{l}\text { A: }-0.045 \\
\text { B: }-0.064\end{array}$ & $\begin{array}{l}\text { A: }-0.010 \\
\text { B: }-0.123\end{array}$ & $\begin{array}{l}\text { A: } 0.080 \\
\text { B: }-0.113\end{array}$ & $\begin{array}{l}\text { A: } 0.041 \\
\text { B: } 0.204\end{array}$ \\
\hline $\mathrm{BMI}, \mathrm{kg} / \mathrm{m}^{2}$ & $\begin{array}{l}\text { A: } 0.057 \\
\text { B: }-0.045\end{array}$ & $\begin{array}{l}\text { A: } 0.224 \\
\text { B: }-0.069\end{array}$ & $\begin{array}{l}\text { A: } 0.156 \\
\text { B: } 0.015\end{array}$ & $\begin{array}{l}\text { A: } 0.093 \\
\text { B: }-0.187\end{array}$ & $\begin{array}{l}\text { A: } 0.207 \\
\text { B: } 0.100\end{array}$ & $\begin{array}{l}\text { A: } 0.025 \\
\text { B: } 0.160\end{array}$ \\
\hline Energy, kJ & $\begin{array}{l}\text { A: } 0.159 \\
\text { B: } 0.005\end{array}$ & $\begin{array}{l}\text { A: } 0.310^{*} \\
\text { B: } 0.054\end{array}$ & $\begin{array}{l}\text { A: } 0.343^{*} \\
\text { B: } 0.065\end{array}$ & $\begin{array}{l}\text { A: } 0.102 \\
\text { B: }-0.102\end{array}$ & $\begin{array}{l}\text { A: } 0.115 \\
\text { B: } 0.023\end{array}$ & $\begin{array}{l}\text { A: }-0.163 \\
\text { B: }-0.059\end{array}$ \\
\hline Protein, $\mathrm{g}$ & $\begin{array}{l}\text { A: } 0.152 \\
\text { B: }-0.195\end{array}$ & $\begin{array}{l}\text { A: } 0.190 \\
\text { B: }-0.025\end{array}$ & $\begin{array}{l}\text { A: } 0.289^{*} \\
\text { B: }-0.047\end{array}$ & $\begin{array}{l}\text { A: }-0.062 \\
\text { B: }-0.099\end{array}$ & $\begin{array}{l}\text { A: } 0.167 \\
\text { B: } 0.008\end{array}$ & $\begin{array}{l}\text { A: }-0.047 \\
\text { B: } 0.012\end{array}$ \\
\hline Fat, $g$ & $\begin{array}{l}\text { A: } 0.057 \\
\text { B: } 0.060\end{array}$ & $\begin{array}{l}\text { A: } 0.247 \\
\text { B: } 0.031\end{array}$ & $\begin{array}{l}\text { A: } 0.293^{*} \\
\text { B: } 0.059\end{array}$ & $\begin{array}{l}\text { A: } 0.019 \\
\text { B: }-0.178\end{array}$ & $\begin{array}{l}\text { A: } 0.215 \\
\text { B: }-0.015\end{array}$ & $\begin{array}{l}\text { A: }-0.093 \\
\text { B: }-0.077\end{array}$ \\
\hline Carbohydrate, $g$ & $\begin{array}{l}\text { A: } 0.194 \\
\text { B: } 0.097\end{array}$ & $\begin{array}{l}\text { A: } 0.297^{*} \\
\text { B: } 0.094\end{array}$ & $\begin{array}{l}\text { A: } 0.312^{*} \\
\text { B: } 0.155\end{array}$ & $\begin{array}{l}\text { A: } 0.107 \\
\text { B: } 0.006\end{array}$ & $\begin{array}{l}\text { A: } 0.077 \\
\text { B: } 0.053\end{array}$ & $\begin{array}{l}\text { A: }-0.170 \\
\text { B: }-0.009\end{array}$ \\
\hline Sugar, g & $\begin{array}{l}\text { A: } 0.102 \\
\text { B: } 0.118\end{array}$ & $\begin{array}{l}\text { A: } 0.259 \\
\text { B: } 0.137\end{array}$ & $\begin{array}{l}\text { A: } 0.251 \\
\text { B: } 0.103\end{array}$ & $\begin{array}{l}\text { A: }-0.029 \\
\text { B: }-0.077\end{array}$ & $\begin{array}{l}\text { A: } 0.066 \\
\text { B: }-0.018\end{array}$ & $\begin{array}{l}\text { A: }-0.112 \\
\text { B: }-0.081\end{array}$ \\
\hline Fiber, g & $\begin{array}{l}\text { A: } 0.163 \\
\text { B: }-0.004\end{array}$ & $\begin{array}{l}\text { A: } 0.194 \\
\text { B: }-0.005\end{array}$ & $\begin{array}{l}\text { A: } 0.166 \\
\text { B: } 0.010\end{array}$ & $\begin{array}{l}\text { A: } 0.194 \\
\text { B: }-0.057\end{array}$ & $\begin{array}{l}\text { A: } 0.076 \\
\text { B: } 0.062\end{array}$ & $\begin{array}{l}\text { A: }-0.177 \\
\text { B: }-0.022\end{array}$ \\
\hline Water total, g & $\begin{array}{l}\text { A: } 0.176 \\
\text { B: }-0.081\end{array}$ & $\begin{array}{l}\text { A: } 0.240 \\
\text { B: }-0.041\end{array}$ & $\begin{array}{l}\text { A: } 0.186 \\
\text { B: }-0.017\end{array}$ & $\begin{array}{l}\text { A: }-0.010 \\
\text { B: } 0.047\end{array}$ & $\begin{array}{l}\text { A: } 0.167 \\
\text { B: }-0.026\end{array}$ & $\begin{array}{l}\text { A: }-0.214 \\
\text { B: } 0.092\end{array}$ \\
\hline Food and beverages total, $\mathrm{g}$ & $\begin{array}{l}\text { A: } 0.168 \\
\text { B: }-0.031\end{array}$ & $\begin{array}{l}\text { A: } 0.282^{*} \\
\text { B: } 0.035\end{array}$ & $\begin{array}{l}\text { A: } 0.247 \\
\text { B: } 0.131\end{array}$ & $\begin{array}{l}\text { A: } 0.026 \\
\text { B: } 0.072\end{array}$ & $\begin{array}{l}\text { A: } 0.178 \\
\text { B: } 0.073\end{array}$ & $\begin{array}{l}\text { A: }-0.216 \\
\text { B: } 0.099\end{array}$ \\
\hline FTS & $\begin{array}{l}\text { A: }-0.298^{*} \\
\text { B: }-0.358^{* *}\end{array}$ & $\begin{array}{l}\text { A: }-0.376^{* *} \\
\text { B: }-0.399^{* *}\end{array}$ & $\begin{array}{l}\text { A: }-0.304^{*} \\
\text { B: }-0.206\end{array}$ & $\begin{array}{l}\text { A: }-0.353^{* *} \\
\text { B: } 0.116\end{array}$ & $\begin{array}{l}\text { A: }-0.335^{*} \\
\text { B: }-0.016\end{array}$ & $\begin{array}{l}\text { A: } 1.000 \\
\text { B: } 1.000\end{array}$ \\
\hline
\end{tabular}

Correlations are given as Spearman's rho: A: Pre-surgery; B: 6 months post-surgery. ${ }^{*}$ Statistically significant $p<0.05 . * *$ Statistically significant $p \leq 0.01$ GSRS-IBS: Gastrointestinal Symptom Rating Scale-Irritable Bowel Syndrome (Increasing values indicates increasing symptoms). FTS: Food Tolerance Score (Increasing values indicates better tolerance)

significantly differently between the groups (all P-values $>0.05$ ). The exception was BMI, which was significantly higher in the RYGB group compared to the VSG group [42.1 (3.42) vs. 39.7 (3.13), $P=0.039$ ]. BMI remained higher, but not significantly, also at the 6 month follow-up [30.2 (3.67) vs. 28.1 (3.42), $P=0.089$ ]. Table 4 shows the changes in GI symptoms and the FTS from pre-to post surgery in each of the surgery groups, as well as comparisons between the groups. GSRS-IBS satiety increased significantly in both groups, but significantly more so in the VSG - than the RYGB-group. Neither the FTS (Table 4), nor its specific items (data not shown), differed significantly between the groups at any time point. However, between-group comparisons of the changes from pre-to post-surgery, revealed significant differences in the changes of the $V / R / R$ score $(P=$ 0.009): From pre- to post-surgery, the $V / R / R$ score increased significantly in the RYGB group and declined in the VSG group; the differences in the changes were in disfavour of the VSG group (Fig. 1).

\section{Discussion}

\section{Changes in $\mathrm{Gl}$ symptoms and food tolerance}

Of five GI symptom dimensions investigated in the present study; GSRS-IBS pain, -bloating, -constipation, -diarrhea and -satiety, a significant increase post-operative was seen

Table 4 Gastrointestinal symptoms and food tolerance before and 6 months after the surgery in the two surgery groups

\begin{tabular}{|c|c|c|c|c|}
\hline & \multicolumn{2}{|l|}{ Pre-surgery } & \multicolumn{2}{|c|}{6 months post-surgery } \\
\hline & RYGB & VSG & RYGB & VSG \\
\hline GSRS-IBS-Pain (1-7) & 1.50 (1.00 to 2.50$)$ & 1.00 (1.00 to 2.00$)$ & 2.00 (1.00 to 2.50$)$ & $2.50(1.00$ to 3.00$) c^{*}$ \\
\hline GSRS-IBS-Satiety (1-7) & $1.00(1.00$ to 1.50$)$ & 1.00 (1.00 to 1.00$)$ & $2.00(1.50$ to 3.00$)$ & $3.00(2.50$ to 4.00$) a^{*}, b^{*}, c^{*}, d^{*}$ \\
\hline GSRS-IBS-Bloating (1-7) & 2.00 (1.25 to 3.08$)$ & 1.67 (1.00 to 2.33) & 2.33 (1.67 to 3.33$)$ & 1.67 (1.33 to 3.00$)$ \\
\hline GSRS-IBS-Constipation (1-7) & 1.00 (1.00 to 2.00$)$ & $1.00(1.00$ to 1.00$)$ & 1.00 (1.00 to 2.50$)$ & $1.00(1.00$ to 3.50$) c^{*}$ \\
\hline GSRS-IBS-Diarrhea (1-7) & 1.25 (1.00 to 2.00$)$ & $1.00(1.00 \text { to } 1.50)^{a^{*}}$ & 1.75 (1.25 to 2.25$)$ & $1.25(1.00$ to 1.75$)$ \\
\hline FTS $(1-27)$ & 24.0 (22.0 to 26.0$)$ & 25.5 (23.0 to 27.0$)$ & 23.0 (20.0 to 26.0$)$ & $20.0(19.0 \text { to } 24.2)^{c^{*}}$ \\
\hline
\end{tabular}

Data are given as median (25-75 percentiles). Mann-Whitney U-test (between group comparisons); Wilcoxon Signed Rank Test (within group comparison of changes). ${ }^{*}$ Statistically significant $p<0.05:{ }^{\text {a }}$ RYGB vs. VSG; ${ }^{\text {b }}$ Changes pre-to post-surgery within group (RYGB); ${ }^{\mathrm{c}}$ Changes pre-to post-surgery within group (VSG); ${ }^{d}$ between-group comparisons (RYGB vs. VSG) of the changes pre-to post-surgery. GSRS-IBS: Gastrointestinal Symptom Rating Scale-Irritable Bowel Syndrome (range 1-7: Increasing values indicates increasing symptoms). FTS: Food Tolerance Score (range 1-27: Increasing values indicates better tolerance) 


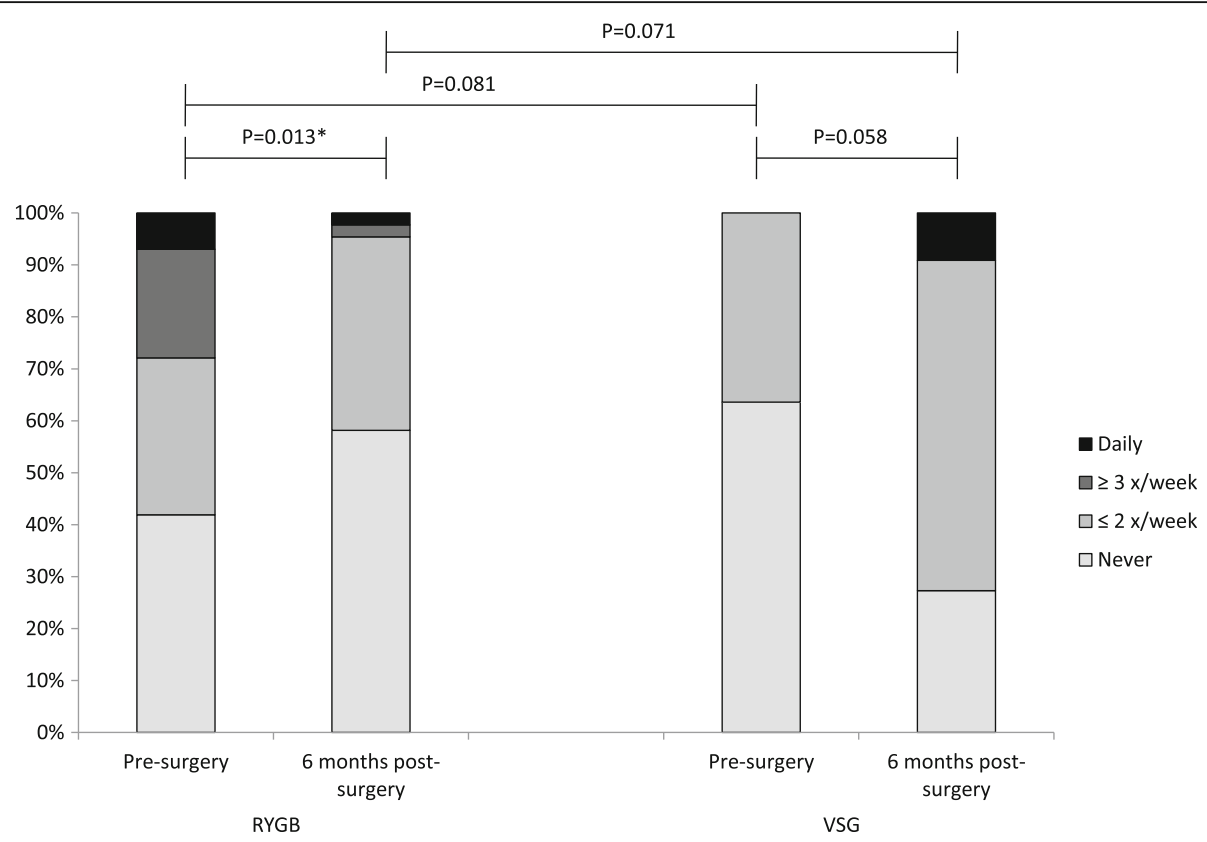

Fig. 1 The figure shows the frequency (\%) of vomiting/regurgitation/reflux pre-and post surgery for each of the surgery groups (RYGB: Roux-en-Y Gastric Bypass and VSG: Vertical Sleeve Gastrectomy). P-values are given for the within-group changes (pre-to post surgery) as well as comparisons between the two surgery groups at each time point. *Statistically significant $p<0.05$

for satiety and constipation. In general, increased satiety is considered a desirable effect of these surgeries, as it may aid in the restriction of food intake and thereby facilitate weight loss. Suggested mechanisms include restriction of gastric volume and modifications of GI hormones involved in the regulation of hunger and satiety [18]. There is a lack of tools developed specifically to address GI symptoms in obese patients before and after weight loss surgeries. Thus, some of the questionnaire items, such as satiety, may have different connotations in patients with functional- or organic GI disorders compared to patients after weight loss surgery. It is therefore not known if the increased satiety was perceived as discomfort, equivalent to what has been reported in patients with IBS [15]. In line with previous studies $[8,10,11,16,19,20]$, food intolerance was a common complication after the surgery. The finding of a correlation between increased satiety and reduced food tolerance in the present study implies that the increased satiety was in part an unfavorable outcome. However, satisfaction about current food intake was rated high ( 25 and 75 percentiles corresponding to "good" and "excellent") both prior to the surgery and at the 6 month follow-up.

Other studies on GI symptoms following weight-loss surgery have provided mixed findings [8, 10, 21-30]. This may partly relate to differences in the study design (e.g. cross-sectional vs. longitudinal), different tools used for the evaluation of GI symptoms and time elapsed since the surgery. Among the longitudinal studies, Ballem $\mathrm{N}$. et al. found a trend towards decreased passing of stools 1-5 years after RYGB [22]. Other symptoms improved or remained unchanged [22]. Afshar S. et al. also found a reduced frequency of bowel motions and a change towards firmer stools for a median of 6.4 months following RYGB and VSG [21]. These results are in agreement with the present findings. In contrast, Potoczna N. et al. found that flatulence and diarrhea increased a median of 2.1 years following RYGB surgery [29]. Others reported an improvement in several GI symptoms $3-12$ months post-operatively [23, 28, 30].

\section{Associations between Gl symptoms, food tolerance, weight, $\mathrm{BMI}$ and dietary intake}

There is a lack of studies examining associations between diet and GI symptoms before and after weight loss surgery. In the present study, total energy intake was reduced by $\sim 46 \%$ from pre-to post-surgery, with similar reductions in each of the energy-yielding nutrients. There were no associations either between the reduced energy intakes and changes in GI symptoms, or between weight- or BMI loss and changes in GI symptoms, including satiety. The reduction in food tolerance correlated with the reduction in weight and BMI, but not with the reduction in total energy intake or specific nutrients. However, the impact of food intolerance on the dietary intake in the earlier post-operative period was not examined. In general, food tolerance improves with time $[19,20]$ and it has been shown that patients can establish a diet of nutritional value that is close to 
that of the general population after a few months of adaption [11].

Along with the reduction in total energy intake, dietary fiber was reduced by $\sim 38 \%$ and total water/fluid intake was reduced by $\sim 30 \%$. The reduction in dietary fiber along with increased symptoms of constipation pre-to post surgery is in line with the study by Afshar S. et al. [21]. However, neither the change in fiber intake, nor the change in water intake, correlated with the change in constipation in the present study. The use of dietary supplements, such as iron, could be another cause of constipation in the post-bariatric patient [31].

Before the surgery, total energy intake correlated significantly with bloating and abdominal pain. Bloating correlated with all of the individual energy yielding nutrients, whereas pain correlated significantly with carbohydrates only. Abdominal pain also correlated with the total amount of food and beverages ingested. Different mechanisms may explain these associations: Increased oral intake could result in gastric distension and abdominal pain [23]. Of the energy yielding nutrients, fat may delay intestinal gas transport and result in abdominal distension [32]. Moreover, total energy intake [33], as well as a "western"/"fast food" dietary pattern characterized by fatty and sugary products, has been associated with the Irritable Bowel Syndrome [34]. The association between carbohydrates and symptoms could possibly also be due to a high load of poorly absorbable and easily fermentable short-chain carbohydrates [35]. Specific dietary patterns were however not explored in the present study. Despite the significant reductions in total food-, energy- and macronutrient intakes, the symptom scores for pain and bloating remained stable after the surgery. Also, at the 6 months follow-up, the symptoms were no longer associated with the dietary intakes. In all, these results suggest that surgically induced changes were responsible for the maintenance, increase or new-onset of symptoms. Factors such as meal size, speed of eating and degree of mastication could also play a role for the degree of GI symptoms and food intolerance after the surgery $[36,37]$, but were not evaluated in the present study. The increase in constipation and satiety post-surgery may as well have induced more symptoms of bloating and/or pain. On the other hand, significant correlations were seen between the change in dietary fat intake and change in bloating, and between the change in sugar intake and change in abdominal pain (the greater the reductions in these macronutrients, the greater the reduction in symptoms), suggesting that at least a sub-group of patients benefited from the dietary modifications. Relevant to this finding is the study by Petereit R. et al., which found that GI symptoms improved post-RYGB along with changes in eating behavior (increased cognitive restraint and decreased uncontrolled and emotional eating) [28]. Changes in eating behavior were however not addressed in the present study. Moreover, a recently published study by our group reported a reduction in overall symptoms, diarrhea and bloating during the pre-operative conservative weight loss intervention [17]. A limitation is that dietary data was recorded only once during that time period, and correlations between the changes in diet and changes in bowel symptoms could therefore not be performed [17].

\section{RYGB vs. VSG}

There is a lack of longitudinal studies comparing changes in specific GI symptoms between patients that underwent RYGB and patients that underwent VSG. Some studies found that flatulence and diarrhea were more common after mixed/malabsorptive procedures, whereas constipation was more common after purely restrictive procedures $[24,29]$. Such differences between the surgery groups were not seen in the present study. However, analyses of within-group changes showed a significant worsening of constipation in the VSG group, but not in the RYGB group. This was due to a non-significantly lower symptom score at baseline and a non-significantly higher symptom score at follow-up in the VSG group compared to the RYGB group. Similar results were obtained for the change in the score for abdominal pain and food tolerance. Thus, procedure specific effects on GI symptoms cannot be excluded, and the present results highlight the need for paired data when evaluating outcomes after the surgery.

The dimension "satiety", which increased significantly after both procedures, was also more notable after VSG than after RYGB. We are not aware of other studies that used the GSRS-IBS questionnaire after weight loss surgery. Satiety is unique to this questionnaire and direct comparisons to other studies were not possible. The GSRS-IBS questionnaire addresses the degree of satiety after food intake in general (feeling full shortly after meal initiation, as well as feeling full even for a long period of time after stopped eating) [15]. By the use of Visual Analogue Scales for satiety pre-and post-operatively, Valderas JP et al. [18] and Yousseif A et al. [38] found that RYGB and VSG surgeries produced a significant $[18,38]$ and similar [38] (between-group comparisons of the changes were not reported by Valderas et al.) increase in postprandial satiety. However, these studies measured nutrient stimulated satiety/fullness perception after a standard liquid test meal (AUC ${ }_{0-180}$ ). Time elapsed since the surgery was 8 weeks [18], 6 and 12 weeks [38] respectively. In the present study, patients were evaluated 6 months post-surgery, i.e. at a time point when solid foods had been introduced. Thus, differences in the perception of satiety between the two surgery groups may 
perhaps depend on the texture of the food. However, more research in this area is needed.

Results from the food tolerance questionnaire showed that the frequency of $V / R / R$ was significantly improved in the RYGB group and marginally worsened in the VSG group. Pre-operatively, none of the patients scheduled for VSG presented with frequent or daily symptoms of $\mathrm{V} / \mathrm{R} / \mathrm{R}$ compared to approximately $1 / 3$ in the RYGB group. Given current evidence which suggests that gastroesophageal reflux is attenuated after RYGB [39], the presence of this symptom is usually considered when patients are counseled to either procedure. This indicates that reflux/regurgitation rather than vomiting was the predominant symptom, with improvement post-RYGB. Although the literature has been ambivalent; several studies have also shown a worsening or new onset of reflux symptoms after VSG [40]. Moreover, results from two recent randomized clinical trials, with a follow-up period of 5 years, both found that severe reflux was a main reason for reoperation in the VSG group [41, 42].

\section{Strengths and limitations}

The small sample size, in particular the low number of VSG patients, reduced the statistical power of the study. The presence of type I statistical errors can also not be excluded as the study was considered explorative and adjustments for multiple tests were not performed. Strength of the study was the longitudinal design, with paired samples and comparisons of changes between the surgery groups. The use of validated instruments for the measurement of GI symptoms, food intolerance and dietary intakes also represents strengths of the study. A limitation is that the GSRS-IBS, unlike the original GSRS from which it is derived, does not contain questions about upper GI symptoms. This limitation was partly compensated for by the use of the food tolerance questionnaire, which addresses the frequency of $V / R / R$.

\section{Conclusion}

Constipation and satiety increased and food tolerance decreased 6 months after the surgery. The changes were not associated with the alterations in diet, such as the reduced intakes of energy, fiber and fluid, but food intolerance was associated with total weight loss. Satiety increased more after the purely restrictive procedure (VSG) than after the mixed procedure (RYGB) and satiety correlated with an overall reduction in food tolerance. The frequency of $V / R /$ $\mathrm{R}$ also increased marginally after VSG, but declined significantly after RYGB. Abdominal pain and bloating correlated with total energy intake before the surgery, but not 6 months after the surgery. Whether alterations in diet such as increased intakes of energy dense foods could result in more symptoms with longer duration of follow-up remain to be explored.

\section{Abbreviations}

BMI: Body Mass Index; FFQ: Food Frequency Questionnaire; FTS: Food

Tolerance Score; Gl: Gastrointestinal; GSRS-IBS: Gastrointestinal Symptom Rating Scale-Irritable Bowel Syndrome; RYGB: Roux-en-Y Gastric Bypass; V/R/ R: Vomiting/Regurgitation/Reflux; VSG: Vertical Sleeve Gastrectomy

\section{Acknowledgements}

The authors want to thank the following co-workers at Innlandet Hospital Trust, Gjøvik: Janne Dahlby Rostad (senior nursing officer at the unit for morbid obesity) for tailoring the practical work to the research activities; $d r$. Martin Aasbrenn (physician, PhD. student) and Anja Byfuglien (study nurse) for patient inclusion and practical work, and dr. Jan Lambrecht (surgeon) for providing a description of the surgical procedures.

\section{Availability of data and material}

Case report forms on paper were used for collection of the clinical data and are all safely stored. The data were transferred manually to SPSS for statistical analyses. The data files are stored by Innlandet Hospital Trust, Brumunddal, Norway, on a server with security according to the rules given by The Norwegian Data Protection Authority, P.O. Box 8177 Dep. NO-0034 Oslo, Norway. The dataset used in the current study are available on reasonable request to the corresponding author.

\section{Funding}

The study has received funding from Innlandet Hospital Trust, Brumunddal, Norway.

\section{Authors' contributions \\ A.S.K. and P.G.F. planned and designed the study. A.S.K. performed statistical analyses, interpreted the data and drafted the manuscript. P.G.F. interpreted the data, revised the manuscript critically for important intellectual content and is the guarantor of the study. Both authors read and approved the final manuscript.}

\section{Ethics approval and consent to participate}

The study was approved by the Regional Committee for Medical and Health Research Ethics in South-eastern Norway (number 2012/966) and written informed consent was obtained from each participant.

\section{Consent for publication}

Not applicable.

\section{Competing interests}

The authors declare that they have no competing interests.

\section{Publisher's Note}

Springer Nature remains neutral with regard to jurisdictional claims in published maps and institutional affiliations.

\section{Author details \\ ${ }^{1}$ Department of Surgery, Innlandet Hospital Trust, Kyrre Greppsgate 11, 2819 Gjøvik, Norway. ²Department of Research, Innlandet Hospital Trust, Brumunddal, Norway. ${ }^{3}$ Unit for Applied Clinical Research, Department of Clinical and Molecular Medicine, Faculty of Medicine and Health Sciences, Norwegian University of Science and Technology, Trondheim, Norway.}

Received: 27 April 2018 Accepted: 14 August 2018

Published online: 03 December 2018

\section{References}

1. Gloy VL, Briel M, Bhatt DL, Kashyap SR, Schauer PR, Mingrone G, Bucher HC, Nordmann AJ. Bariatric surgery versus non-surgical treatment for obesity: a systematic review and meta-analysis of randomised controlled trials. BMJ. 2013;347:f5934

2. Jakobsen GS, Smastuen MC, Sandbu R, Nordstrand N, Hofso D, Lindberg M, Hertel JK, Hjelmesaeth J. Association of Bariatric Surgery vs medical obesity treatment with long-term medical complications and obesity-related comorbidities. JAMA. 2018;319:291-301.

3. Aasbrenn M, Hogestol I, Eribe I, Kristinsson J, Lydersen S, Mala T, Farup PG. Prevalence and predictors of irritable bowel syndrome in patients with morbid obesity: a cross-sectional study. BMC Obes. 2017;4:22. 
4. Camilleri M, Malhi $H$, Acosta A. Gastrointestinal complications of obesity. Gastroenterology. 2017;152:1656-70.

5. Pickett-Blakely O. Obesity and irritable bowel syndrome: a comprehensive review. Gastroenterol Hepatol (N Y). 2014;10:411-6.

6. Talley NJ, Quan C, Jones MP, Horowitz M. Association of upper and lower gastrointestinal tract symptoms with body mass index in an Australian cohort. Neurogastroenterol Motil. 2004;16:413-9.

7. Aro P, Ronkainen J, Talley NJ, Storskrubb T, Bolling-Sternevald E, Agreus L. Body mass index and chronic unexplained gastrointestinal symptoms: an adult endoscopic population based study. Gut. 2005;54:1377-83.

8. Boerlage TC, van de Laar AW, Westerlaken S, Gerdes VE, Brandjes DP. Gastrointestinal symptoms and food intolerance 2 years after laparoscopic roux-en-Y gastric bypass for morbid obesity. Br J Surg. 2017;104:393-400.

9. Godoy CM, Caetano AL, Viana KR, Godoy EP, Barbosa AL, Ferraz EM. Food tolerance in patients submitted to gastric bypass: the importance of using an integrated and interdisciplinary approach. Obes Surg. 2012;22:124-30.

10. Goldenshluger M, Goldenshluger A, Keinan-Boker L, Cohen MJ, Ben-Porat T, Gerasi H, Amun M, Abu-Gazala M, Khalaileh A, Mintz Y, Elazary R. Postoperative outcomes, weight loss predictors, and late gastrointestinal symptoms following laparoscopic sleeve gastrectomy. J Gastrointest Surg. 2017;21:2009-15.

11. Ortega J, Ortega-Evangelio G, Cassinello N, Sebastia V. What are obese patients able to eat after roux-en-Y gastric bypass? Obes Facts. 2012:5:339-48.

12. Andersen LF, Solvoll K, Johansson LR, Salminen I, Aro A, Drevon CA. Evaluation of a food frequency questionnaire with weighed records, fatty acids, and alpha-tocopherol in adipose tissue and serum. Am J Epidemiol. 1999;150:75-87.

13. Carlsen MH, Lillegaard IT, Karlsen A, Blomhoff R, Drevon CA, Andersen LF. Evaluation of energy and dietary intake estimates from a food frequency questionnaire using independent energy expenditure measurement and weighed food records. Nutr J. 2010;9:37.

14. Matvaretabellen 2016. Mattilsynet, Helsedirektoratet og Universitetet i Oslo http://www.matvaretabellen.no/. Accessed 22 April: 2018.

15. Wiklund IK, Fullerton S, Hawkey CJ, Jones RH, Longstreth GF, Mayer EA, Peacock RA, Wilson IK, Naesdal J. An irritable bowel syndrome-specific symptom questionnaire: development and validation. Scand J Gastroenterol. 2003;38:947-54.

16. Suter M, Calmes JM, Paroz A, Giusti V. A new questionnaire for quick assessment of food tolerance after bariatric surgery. Obes Surg. 2007;17:2-8.

17. Aasbrenn M, Lydersen S, Farup PG. A conservative weight loss intervention relieves bowel symptoms in morbidly obese subjects with irritable bowel syndrome: a prospective cohort study. J Obes. 2018;2018:3732753.

18. Valderas JP, Irribarra V, Boza C, de la Cruz R, Liberona Y, Acosta AM, Yolito M, Maiz A. Medical and surgical treatments for obesity have opposite effects on peptide $Y$ Y and appetite: a prospective study controlled for weight loss. J Clin Endocrinol Metab. 2010;95:1069-75.

19. Ruiz-Tovar J, Bozhychko M, Del-Campo JM, Boix E, Zubiaga L, Munoz JL, Llavero C. Changes in frequency intake of foods in patients undergoing sleeve gastrectomy and following a strict dietary control. Obes Surg. 2017;28:1659-64.

20. Stumpf MA, Rodrigues MR, Kluthcovsky AC, Travalini F, Milleo FQ. Analysis of food tolerance in patients submitted to bariatric surgery using the questionnaire quality of alimentation. Arq Bras Cir Dig. 2015;28(Suppl 1):79-83.

21. Afshar S, Kelly SB, Seymour K, Woodcock S, Werner AD, Mathers JC. The effects of bariatric procedures on bowel habit. Obes Surg. 2016;26:2348-54.

22. Ballem N, Yellumahanthi K, Wolfe M, Wesley MM, Clements RH. Gastrointestinal symptom improvement after roux-en-Y gastric bypass: longterm analysis. Surg Obes Relat Dis. 2009:5:553-8.

23. Clements RH, Gonzalez QH, Foster A, Richards WO, McDowell J, Bondora A, Laws HL. Gastrointestinal symptoms are more intense in morbidly obese patients and are improved with laparoscopic roux-en-Y gastric bypass. Obes Surg. 2003;13:610-4.

24. El LS, Safadi B, Olabi A. The effect of roux-en-Y gastric bypass and sleeve gastrectomy surgery on dietary intake, food preferences, and gastrointestinal symptoms in post-surgical morbidly obese Lebanese subjects: a cross-sectional pilot study. Obes Surg. 2015;25:2393-9.

25. Gribsholt SB, Pedersen AM, Svensson E, Thomsen RW, Richelsen B. Prevalence of self-reported symptoms after gastric bypass surgery for obesity. JAMA Surg. 2016;151:504-11.

26. Hogestol IK, Chahal-Kummen M, Eribe I, Brunborg C, Stubhaug A, Hewitt S, Kristinsson J, Mala T. Chronic abdominal pain and symptoms 5 years after gastric bypass for morbid obesity. Obes Surg. 2017;27:1438-45.
27. Nickel F, Schmidt L, Bruckner T, Billeter AT, Kenngott HG, Muller-Stich BP, Fischer L. Gastrointestinal quality of life improves significantly after sleeve gastrectomy and roux-en-Y gastric bypass-a prospective cross-sectional study within a 2-year follow-up. Obes Surg. 2017;27:1292-7.

28. Petereit R, Jonaitis $L$, Kupcinskas $L$, Maleckas A. Gastrointestinal symptoms and eating behavior among morbidly obese patients undergoing roux-en-Y gastric bypass. Medicina (Kaunas ). 2014;50:118-23.

29. Potoczna N, Harfmann S, Steffen R, Briggs R, Bieri N, Horber FF. Bowel habits after bariatric surgery. Obes Surg. 2008;18:1287-96.

30. Sileri P, Franceschilli L, Cadeddu F, De LE, D'Ugo S, Tognoni V, Camperchioli I, Benavoli D, Di LN, Gaspari AL, Gentileschi P. Prevalence of defaecatory disorders in morbidly obese patients before and after bariatric surgery. J Gastrointest Surg. 2012;16:62-6.

31. Sahebzamani FM, Berarducci A, Murr MM. Malabsorption anemia and iron supplement induced constipation in post-roux-en-Y gastric bypass (RYGB) patients. J Am Assoc Nurse Pract. 2013;25:634-40.

32. Serra J, Salvioli B, Azpiroz F, Malagelada JR. Lipid-induced intestinal gas retention in irritable bowel syndrome. Gastroenterology. 2002;123:700-6.

33. Torres MJ, Sabate JM, Bouchoucha M, Buscail C, Hercberg S, Julia C: Food consumption and dietary intakes in 36,448 adults and their association with irritable bowel syndrome: Nutrinet-Sante study. Therap Adv Gastroenterol 2018:11:1756283X17746625.

34. Buscail C, Sabate JM, Bouchoucha M, Kesse-Guyot E, Hercberg S, Benamouzig R, Julia C. Western dietary pattern is associated with irritable bowel syndrome in the French NutriNet cohort. Nutrients. 2017;9:1-13.

35. Camilleri M, Boeckxstaens G. Dietary and pharmacological treatment of abdominal pain in IBS. Gut. 2017;66:966-74.

36. Bavaresco M, Paganini S, Lima TP, Salgado W Jr, Ceneviva R, Dos Santos JE, Nonino-Borges CB. Nutritional course of patients submitted to bariatric surgery. Obes Surg. 2010;20:716-21.

37. Sherf DS, Goldenshluger A, Globus I, Schweiger C, Kessler Y, Kowen SG, BenPorat $T$, Sinai T. Nutritional recommendations for adult bariatric surgery patients: clinical practice. Adv Nutr. 2017;8:382-94.

38. Yousseif $A$, Emmanuel J, Karra E, Millet $Q$, Elkalaawy M, Jenkinson AD, Hashemi M, Adamo M, Finer N, Fiennes AG, Withers DJ, Batterham RL. Differential effects of laparoscopic sleeve gastrectomy and laparoscopic gastric bypass on appetite, circulating acyl-ghrelin, peptide YY3-36 and active GLP-1 levels in non-diabetic humans. Obes Surg. 2014;24:241-52.

39. El-Hadi M, Birch DW, Gill RS, Karmali S. The effect of bariatric surgery on gastroesophageal reflux disease. Can J Surg. 2014;57:139-44.

40. Stenard F, lannelli A. Laparoscopic sleeve gastrectomy and gastroesophageal reflux. World J Gastroenterol. 2015;21:10348-57.

41. Peterli R, Wolnerhanssen BK, Peters T, Vetter D, Kroll D, Borbely $Y$, Schultes B, Beglinger C, Drewe J, Schiesser M, Nett P, Bueter M. Effect of laparoscopic sleeve gastrectomy vs laparoscopic roux-en-Y gastric bypass on weight loss in patients with morbid obesity: the SM-BOSS randomized clinical trial. JAMA. 2018;319:255-65.

42. Salminen $P$, Helmio $M$, Ovaska J, Juuti $A$, Leivonen $M$, Peromaa-Haavisto $P$ Hurme S, Soinio M, Nuutila P, Victorzon M. Effect of laparoscopic sleeve gastrectomy vs laparoscopic roux-en-Y gastric bypass on weight loss at 5 years among patients with morbid obesity: the SLEEVEPASS randomized clinical trial. JAMA. 2018:319:241-54.

Ready to submit your research? Choose BMC and benefit from:

- fast, convenient online submission

- thorough peer review by experienced researchers in your field

- rapid publication on acceptance

- support for research data, including large and complex data types

- gold Open Access which fosters wider collaboration and increased citations

- maximum visibility for your research: over $100 \mathrm{M}$ website views per year

At $\mathrm{BMC}$, research is always in progress.

Learn more biomedcentral.com/submissions 